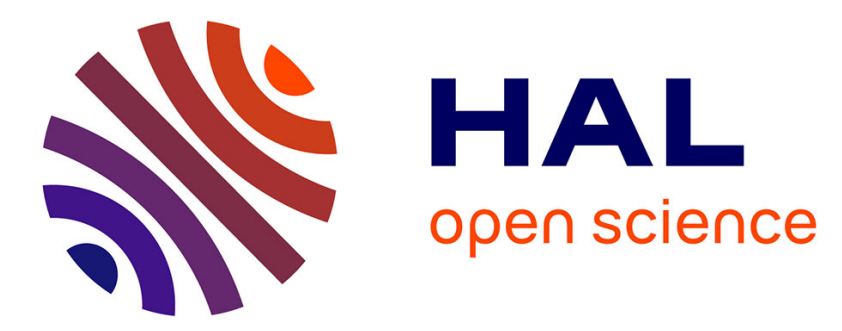

\title{
Individuation and the organization in complex living ecosystem: recursive integration and self-assertion by holon-lymphocytes
}

Véronique Thomas-Vaslin

\section{- To cite this version:}

Véronique Thomas-Vaslin. Individuation and the organization in complex living ecosystem: recursive integration and self-assertion by holon-lymphocytes. Acta Biotheoretica, 2020, CFBT 2018, 10.1007/s10441-019-09364-w . hal-02282163

\section{HAL Id: hal-02282163 \\ https://hal.science/hal-02282163}

Submitted on 9 Sep 2019

HAL is a multi-disciplinary open access archive for the deposit and dissemination of scientific research documents, whether they are published or not. The documents may come from teaching and research institutions in France or abroad, or from public or private research centers.
L'archive ouverte pluridisciplinaire HAL, est destinée au dépôt et à la diffusion de documents scientifiques de niveau recherche, publiés ou non, émanant des établissements d'enseignement et de recherche français ou étrangers, des laboratoires publics ou privés. 


\title{
Individuation and the organization in complex living ecosystem: recursive integration and self-assertion by holon-lymphocytes
}

\author{
Véronique Thomas-Vaslin \\ Sorbonne Université, INSERM, Immunology, Immunopathology, Immunotherapies, UMRS959, F-75013 Paris, \\ France
}

Correspondance :

Dr Véronique Thomas-Vaslin, PhD CNRS

Sorbonne Université -INSERM UMRS 959,

83, Boulevard de l'Hôpital,

F-75013 Paris

veronique.thomas-vaslin@sorbonne-universite.fr

tel: 33(1) 42177468

fax:33(1) 42177462

https://orcid.org/0000-0001-7521-8635

Key words: theoretical biology; organization; complex systems; immune system; individuation; holon; lymphocyte; integration; holobiont; ecosystem

\section{Abbreviations:}

DNA: deoxyribonucleic acid ; Ig: Immunoglobulin; CIS: Central Immune System; PIS: Peripheral Immune System

Acknowledgements: I thank P.A. Miquel and A. Ehresmann for helpful discussions. 


\begin{abstract}
Individuation and organization in complex living multi-level ecosystem occurs as dynamical processes from early ontogeny. The notion of living "holon" displaying dynamic self-assertion and integration is used here to explain the ecosystems dynamic processes. The update of the living holon state according to the continuous change of the dynamic system allows for its viability. This is interpreted as adaptation, selection and organization by the human that observes the system at posteriori from its level. Our model concerns the complex dynamics of the adaptive immune system, integrating holon-lymphocytes that collectively preserve the identity and integrity of the organism. Each lymphocyte individualizes as a dynamic holon-lymphocyte, with somatic gene individuation leading to an individual, singular antigen immunoreceptor type, promoting the self-assertion. In turn, the "Immunoception" allows for perception of the environmental antigenic context, thus integration of the holon in its environment. The self-assertion/integration of holon-lymphocyte starts from fetal stages and is influenced by mother Lamarckian acquired historicity transmissions, a requisite for the integrity of the holobiont-organism. We propose a dynamic model of the perception by holon-lymphocyte, and at the supra-clonal level of the immune system functions that sustain the identity and integrity of the holon-holobiont organism.
\end{abstract}


Individuation and the organization in complex living ecosystem: ......................................1

recursive integration and self-assertion by holon-lymphocytes.........................................1

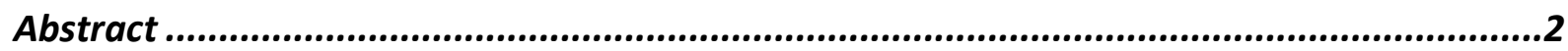

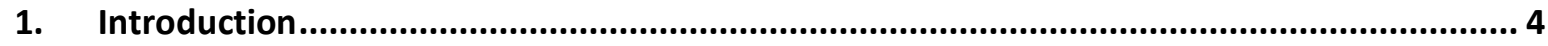

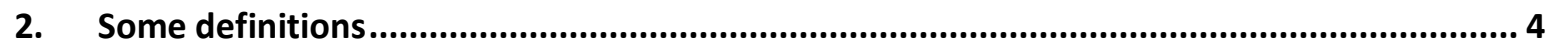

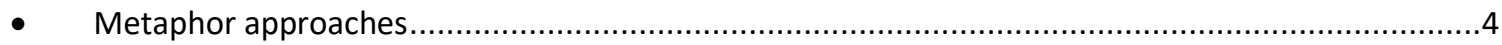

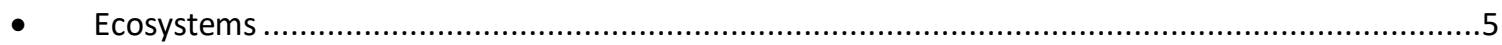

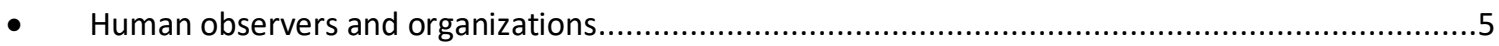

- Cell observer, adaptability versus enablement in organization .............................................

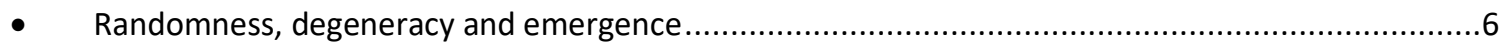

3. A general model of Individuation by recursive self-assertion/integration of heterogeneous cognitive holons with self-organization

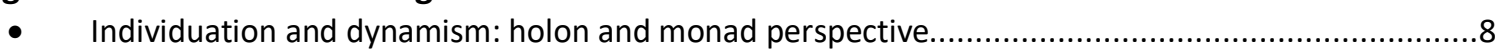

- Complexification with heterogeneous holon-cells and holon-organisms. ......................................9

4. Dynamical processes for the hierarchical organization and individuation of holonlymphocytes and holon-organism for recursive self-assertion and integration............................ 9

- Immunoception and individuation through the dynamic adaptive immune system .......................10

- The immune system: not a defense but a conservation system................................................12

- $\quad$ The holon-lymphocyte individuation at the somatic level, with generation of diversity through

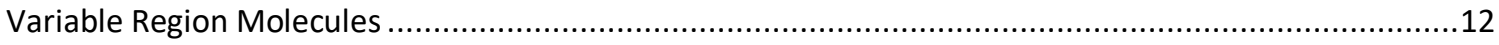

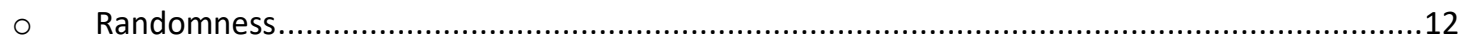

○ Redundancy of molecular receptors and lymphocyte clones ..............................................13

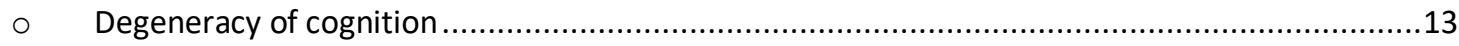

- A connective dynamic network of lymphocytes to organize the Central and Peripheral Immune

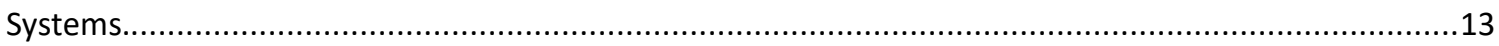

- $\quad$ Completeness of repertoires of lymphocytes for self-assertion and integration. ...........................14

- Self-assertion and integration of the holobiont poly-genomic organism, and Lamarckian

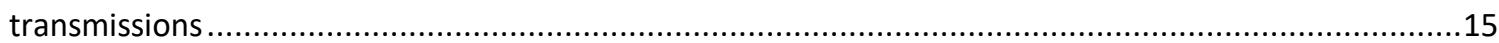

- Balancing the diversity and redundancy of lymphocyte clones for a dialectic equilibrium allowing for

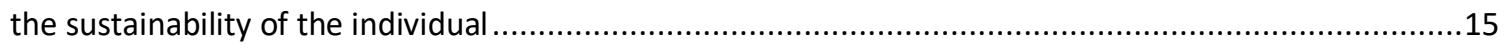

- Individuation emergence: supra-clonal immunological memory and dominant tolerance in the

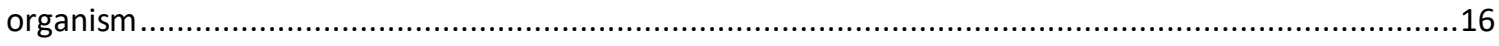

- Impact of aging and environmental perturbations on the self-assertion and integration of holonlymphocytes and holon-organisms

5. A mathematical model of dynamical processes through holon reconfiguration, for self-

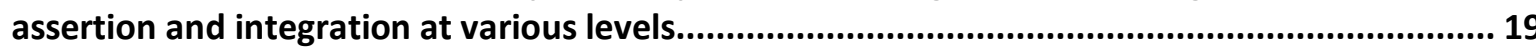

- Generalization of the model of holon at any level of the living system ........................................20

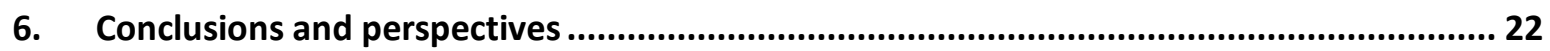

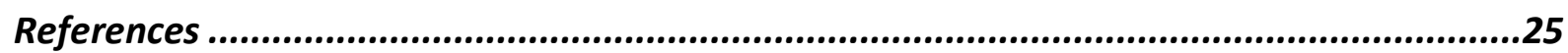




\section{Introduction}

There are missing perceptions of interrelated problems in the living word that require new conception of life and an holistic and ecological worldview, not related to parts but to relations and processes (Capra and Luisi 2014). The notion of processes evolving through the vertical flow of information, in hierarchical levels, is important in relational biology and ecology that are artificially dissociated into different domains of research. Paton pointed (Paton 2002) that "Modem biology has had great success in taking living systems to pieces". Capra proposed a system view of life to give a unified vision (Capra and Luisi 2014). The approach should not be limited on human pyramidal hierarchy, but on nature hierarchy with interweaved networks. The holistic vision with concepts of Holon and holonic networks could help to propose a system thinking (Mella 2009). While the cognitive brain perception is viewed as a unique system of macro perception, the perception of our micro-environment by the cognitive immune system without neurons (Stewart 1993) , (Cohen 1992) is still missing in most approaches. Our misperception of the complexity of living and cognitive networks has consequences for ecosystems and ecological transition.

Here, a paradigm shift with an ecological and holistic thinking, allowing for a better integration of the cognitive immune system in the organization of autopoietic cognitive organisms (Bourgine and Stewart 2004), ecosystems and orgons (Mella 2009) is proposed.

Following this short general introduction on the requirement of a paradigm shift, (1) the manuscript go through (2) some definitions; (3) a general model of individuation, that involves the adaptive immune system, related to the recursive integration and self-assertion by heterogenous "holons"; (4) illustrations of some processes involved in the species evolution and ontogeny for the emergence of the adaptive immune system, a unique cognitive self-organizing system, with perception action of lymphocytes, mandatory for the living of vertebrate organisms; (5) a generic mathematical approach allowing for self-assertion/integration, to integrate heterogeneous micro to macro-level living holons, interweaved in dynamic eco-systems in the biosphere; (6) discussion and perspectives related to the paradigm shift.

\section{Some definitions}

\section{- Metaphor approaches}

The individuation starts early during the ontogeny of natural living multi-cellular organism and even establishes in artificial organizations set up by humans. Bad metaphors are speaking of the "DNA of enterprises" to say that there is an identity of the artificial construction, related to genes and codes. This is a reductionist and simplistic view of living and artificial systems, viewed as entities. It is however important for a human observer to consider complex systems from other levels and scales, to better conceptualize their complexity into integrative models and ecosystem. Information metaphors could be useful when observing and modeling the cellular to ecosystem levels of organization to propose modelling relations (Paton 1996). This requires considering cognitive cells and to have a system thinking, based on network, and not on machines as a metaphor. A paradigm shift from the human-centered view of ecology to deep ecology (Naess 1973) is required. Metaphors on immune system, viewed as a "defense system" or a "war machine" designed to distinguish "self and non-self" were extensively 
criticized (Coutinho et al. 1984; Tauber 2014; Vaz et al. 2006). The generative grammar of immune system was proposed by Niels. K. Jerne in is Nobel lecture (Jerne 1985). It underlines that the immune system combines in a language without brain, the information from its receptor, antigens and the context (Atlan and Cohen 1998). Rather than seeing dichotomy in autoimmunity and self-defense, Tauber proposed that Concinnity: "Harmony in the arrangement or inter-arrangement of parts with respect to the whole" should better describe the immune system functions (Tauber 2014). Self-assertion/integration processes in individual cells and then in organism is considered here not only as a metaphor, but as a mathematical approach to explain the immune system functions.

\section{- Ecosystems}

The definition of ecosystem is often reduced to a complex of units, as organisms or species, and physical factors (Tansley,1935) interacting in a functional community (ONU). If ecosystem characterizes plant and animal communities we are missing unicellular life cells, microbiota ecosystem as network of individual organisms. Conrad pointed that an ecosystem is a process, through a more general definition: " $a$ living system which is capable of sustaining itself indefinitely and without help from any other such system" (Conrad 1983). According to Paton (Paton 2002), vertical information processing is required to integrate all levels through processes, structure and context. Then, in each organism, the immune system is mandatory for organism survival and is included in the ecosystem. But most people ignore the immune system cognitive functions, since this system concerns the unconscious microscopic perception of the environment.

\section{- Human observers and organizations}

A human observer, through its cognitive functions and brain can abstract compartments or processes in a system, and connect them together in time and space, in order to reconstruct its organization. Organization, refers to Robert Rosen relational biology concept of living systems able to metabolize and replicate/repair (Rosen 1958). Ross Ashby also proposed the self-organization theory (Ashby 1962) involving conditionality, constraints, processes and communications through variation and competition. For Conrad, a hierarchical organization and gradualism in ecosystem occurs. This involves functional processes in dissipative open systems, with molecular, cell and organism adaptability and evolution, to function in an uncertain environment (Conrad 1983). This is the result of long-term species evolution, with variations, adaptation and selection processes that have occurred through million years in the ecosystem. Two general principles of organization and variation were proposed to realize biological systems, either organisms (Mossio et al. 2016) through ontogenesis, or larger organized ecosystems (Nunes-Neto 2014), through phylogenesis.

Organization also refers to the global view of the human observer that discovers a posteriori the emergence of the structuration and the functional system. At a high level in ecosystems, it appears "organized" and with a "stable" architecture-driven organization and phenotype. Based on microscopic observations, the human observer proposes abstraction, reconstruction and modeling of multi-level complex systems according to environmental constraints. This occurs through the permanent dynamical energy-dependent processes, leading to cell communication, interactions, within the changing environment, where the cognitive immune system plays an important role, with emerging-trace processes and functions (Thomas-Vaslin 2017). From the viewpoint of an 
external human observer, cells and organisms have some choices, with "adaptability", leading to the concept of efficiency, fitness, competition, stability or instability (Conrad 1983). However, considering the perspective of a microscopic biological observer, as a living cell, internal to multicellular organisms that have evolved during species evolution and during ontogeny, typically up to humans, can change our understanding of the system organization. Then, the current observed "perturbations" of our ecosystem, from our human perspective should lead to turn to a global evaluation of systems (Jacquemart and Thomas-Vaslin 2016).

\section{- Cell observer, adaptability versus enablement in organization}

Cells are the smallest sensitive alive dynamical systems able to integrate flux of changes, allowing them to sense their environment. They have an historicity and an individuality. One can then consider they have a quality of local cell observer inside the living system. At this lowest level, cells do not "organize", have no intention and do not take any decision. However, they are able to explore their dynamic contextual local environment, as "Waddington landscape" (Fagan 2011) that continuously evolves through time. For an external observer they "adapt" their behavior. Longo, Montevil and Kaufmann jointly proposed there is no entailing laws, like in physics with specific causation, but a priori the "enablement" (Longo and Montévil 2013; Longo et al. 2012). Then, cells have a stochastic gene expression and fluctuations at mRNA level. However, for an external observer, they display a stable cell phenotype that is related to the stability of proteins and tissues functions, at the higher level (Corre et al. 2014). Cells, through their "enablement" respond to molecular and cell interactions, and update their state to either reproduce, to change their function (differentiate), or to die by cell suicide. Three types of adaptive immunity emerged during species evolution (Muller et al. 2018). Darwinian immunity represents a major evolutionary transition with emergence of new information systems. Lymphocytes that appeared during species evolution of vertebrates (Flajnik and Kasahara 2010), are exceptional cells : they are more complex than other body cells, enable to extensively diversify by random processes, at the somatic level, by combinatorial diversity. According to the popular "clonal selection theory", selection processes allow them to display adaptive proliferative clonal capacities (Burnet 1957; Jerne 1971; Jerne 1984). However, their adaptive capacities also develop from an internal network of interactive and regulatory cells, distributed in the whole organism, and functional at the cell population level, where cognitive functions with memory emerge as a self-organization.

\section{- Randomness, degeneracy and emergence}

At a low-level, biological components of cells and organisms are highly diversified, heterogeneous but also redundant and permanently change their interconnections with others (Lavelle et al. 2008). Because they display structural and functional degeneracy (Edelman and Gally 2001) they have multiplicity properties. The degeneracy of paths and landscape, creates what is commonly assimilated to "noise". Atlan underlined the variation of information versus time that occurs in self-organization, and that diversity, noise and initial redundancy are the factors of self-organization (Atlan 1974). Atlan and Cohen as immunologists (Atlan and Cohen 1998), considered the germline and random somatic information (noise) for the immune system selforganization and emergence through the multilevel organization of meaning of immunological messages within a given context. Random perturbation in communication processes and translation, can create noise and a decrease of information content at the higher level, according to Shannon information theory. However, noise 
is not an error in biological systems, but is a fundamental feature: fluctuations may enhance the robustness of living systems, while each biological level should integrate fluctuations (Lavelle et al. 2008). Thus, the term of functional randomness inside the organism, seems more relevant than noise. According to Ehresmann (Ehresmann and Vanbremeersch 2007), the structure of network of co-regulators could explain the emergence of various complex links and functions in living systems, above the noise. The structural and functional redundancy with variations, the connectivity of elements, but also the historicity and context, constrain the living system. Under such constraints, the dynamical systems allow for the emergence of behavior and system robustness and resilience. The resilience of living systems depends on their internal organization and perturbations fluxes. As a consequence, the behavior of living systems is not predictable since it depends on the continuous processes, involving "external" and "internal" components. However, from a higher perspective, organization and individuation could appear with a relative stability, classically named homeostatic systems. However, the concept of homeo-dynamism seems more relevant of the dynamics turnover of small part of the system (Yates 1994). The human society often consider that large ecosystems are relative stable and adaptive systems able to absorb perturbations (Colon 2016). However, since small entities permanently turnover, and because of an accelerated rhythm and amplitude of perturbations, the regulations could be altered through disruption. Consequently, perturbations at any level could alter the viability of living systems, according to the viability theory (Aubin et al. 2011). In 1952, Ashby proposed the principle of self-organization in 1947. in "Design for a brain" he explains the unique adaptive behavior of brain, and underlined the feedback, adaptation and selforganization properties. However, as underlined before such properties are not restricted to brain. They also concern the diversified network of receptors that generate the cognitive adaptive immune system, as revealed by Jerne (Jerne 1955; Jerne 1971). The immune system self-organizes at the interface of environment and through the properties of randomness, degeneracy and emergence perceive the microscopic changes in each organism, and adapt its behavior to survive.

\section{A general model of Individuation by recursive self-assertion/integration of heterogeneous cognitive holons with self-organization}

Here, I propose to include the relational dynamical bio-information's exchange and update, intra and inter-cells and organism, in an ecological system. New viewpoints about the ecosystem are then proposed with the integration of the immune system of complex organisms as humans, while these systems are generally studied in separated domains and institutions. The model should integrate the dynamics process of lymphocytes, that control the identity and integrity of organisms, into ecosystems. As a metaphor, one can consider that each lymphocyte individualizes at the somatic level in each organism and represents an individual holon. Collectively, lymphocyte populations, as a network, realize a cognitive system (Vaz 2011) that perceives, reacts, and adapts to the variations of the environmental context of each organism, also represented as a holon. This cognitive adaptive immune system dynamics is at the basis of the antigens cognition, memory and tolerance of molecular and cellular patterns that permanently change across time and tissues in the complex body: the immune system acts as key regulator of the individuation and viability of organisms. By extension, the healthiness of organisms 
and humans interfere with the healthiness of ecosystems. Social-ecosystems and artificial human driven systems, on the other side, can orient or perturb the immune system functions.

Using this concept of self-assertion/integration with dynamic receptive microscopic to macroscopic heterogenous holons, should improve our understanding on how a natural system co-constructs and organizes at various hierarchical and interweaved biological levels. This should include processes through time and space, and how the system is regulated, up to emerging functions, to normally maintain physiological conditions and health state at all levels.

\section{- Individuation and dynamism: holon and monad perspective}

Let us consider individuation as energy transfer, allowing for various dynamical processes insuring the viability of an alive system. This is inspired from Simondon theory of individuation where transformation of forms is required, as a quality or a "tension d'information" to sustain the individuation at various levels of organization ${ }^{1}$. This notion of transformation is quite different from Shannon "theory of information", based on probabilities. Then, individuation would result from iterative interactions, communication and perception between subsystems, occurring in open multi-level biological systems, from cells to multicellular organisms, to macroecosystems. A philosophical concept of "unit" as a monad, with perception and internal changes, but no parts was proposed by Leibniz in 1714. The concept of "holon" was then introduced by Arthur Koestler in 1962, to represent an element of intermediary level, which plays a Janus faced double role, being simultaneously a "whole" and a "part" (Koestler 1968). According to Piero Mella, the holon is also a vital agent that is a part of organizations and even can be absorbed and interact in orgonizations (social holons, human artifacts at various levels) (Mella 2009).

The holon, (at a "level $n$ ") represents both a simple unit (a kind of monad), if compared to entities of higher levels $(n+1)$, but also a complex system, with respect to its lower levels of organization ( $n-1)$, since it has its own internal organization with some interacting parts. Thus, a living-holon belongs to an holarchy that is a multi-level system from a single cell up to multicellular organisms. Each holon has double perception capacities (i) from the lower levels of biological organization, the emergence of internal processes through interactive parts allows for the structure and functions of this biological unit, thus insuring its "self-assertion", (ii) from the higher levels, the immergence of external processes from the external environment influence back the structure and functions of the biological unit, thus insuring the "integration" in the whole ecosystem. As underlined by A. Ehresmann (Ehresmann 2013), a monad (here named holon) preserves its identity although its internal components are

\footnotetext{
${ }^{1}$ G. Simondon, Communication et information 1962 « Être ou ne pas être information ne dépend pas seulement des caractères internes d'une structure ; l'information n'est pas une chose, mais l'opération d'une chose arrivant dans un système et y produisant une transformation. L'information ne peut se définir en dehors de cet acte d'incidence transformatrice et de l'opération de réception ". Translated as "Being or not being information does not depend only on the internal characters of a structure; information is not a thing, but the operation of a thing arriving in a system and producing a transformation. The information can not be defined outside this transformational impact act and the receiving operation"
} 
replaced or repaired. Thus, the perception of complexity depends on the perspective on the system and of the level of observation and abstraction.

\section{- Complexification with heterogeneous holon-cells and holon-organisms.}

The concept of "holon" covers the smallest living structure as cells or bacteria's, up to the multi-cellular organisms. Holons then are intricated in dynamical systems, members of a larger social-ecosystem, all integrated (and integrating) in the wide micro (cells, microbiota) to macro-ecosystems of the biosphere. While artificially studied as different domains, micro and macro systems are thus weaved together, increasing the complexification of emergent functions and the behavior on the various biological levels. The individuation results from emergent processes that look like an organized development in time and space.

Now with the example of mammals' adaptive immune system, I extend the concept of holon to "holonlymphocyte" that develops in the vertebrate immune system, hosted by the holon-organism. Typically, the human is a poly-genomic organism, with a multi-level intricated holarchy, with a combination of genetic and Lamarckian inheritance: it includes body cells those genes are inherited from parents, but also the immune system whose lymphocytes extensively change their receptor germline genes through somatic diversification. Then, the acquired symbiotic microbiota, as bacteria, fungi, protists, viruses, are microscopic holons that compose the multicellular organism. In humans they represent $50 \%$ of the body cells in adults. This leads to the concept of "holobiont" organism (Bordenstein and Theis 2015), the immune system is facing with, to preserve the organism identity and integrity. The concept of trace-processes that evolve during ontogenesis and phylogenesis in an arborescent fractal organization of the holobiont organism was previously illustrated (Thomas-Vaslin 2017). Here I propose that the heterogenous holon-cells are dynamically encapsulated through various levels of organization and processes. They acquire collective emerging functions and transmissions, across time and space (tissues), in and within holon-organisms. The immune system is mandatory for the viability of organisms and influences their healthiness. The immune system performance can also be modified top down, by the humans that extensively interfere with the natural environment.

\section{Dynamical processes for the hierarchical organization and individuation of holon-lymphocytes and holon-organism for recursive self-assertion and integration}

The immune system allows for the integration/self-assertion of the human individual as an "holobiont" organism, with its symbiotic microbiota, in the macro ecosystem. At the lower level, the role of each singular individualized and autonomous lymphocyte, is explained later from development to aging and diseases, with processes of selfassertion/integration in their environment. Each lymphocyte of the immune system acts as a "cell observer" of its environment and is included in networks: lymphocytes have a pattern processing capacity, and the system itself constructs some information from the cell network, reaching a cognitive capacity. This means that the immune system of each organism is able to make some "interpretation" of the evolutive immunological context and patterns or motifs (named antigens) perceived at molecular level. The immune system behave as a self- 
organization without centralization but with distributed heterogenous circulating holons, to preserve the integrity of the host.

The individuation starts from the unique zygote cell after the fecundation, with the first cell divisions, then variation through differentiation into cell lineages during organogenesis, while extensive cell death also occurs (selection). With a diversity of communicating holon-cells, according to various cell types, and the dynamic cell receptor/ligand interactions, "organization" emerges as structured dynamical and reproductive patterns. This leads to emergence of tissues and organs with functions, in the growing constrained holon-organism. In the embryonic organism, the adaptive immune system emerges from the complex differentiation of hematopoietic cells. Lymphopoiesis allows for the differentiation and generation of heterogeneous lymphoid cell types with evolutive phenotypes and functions that regulate each other's, through cooperation and selection. Importantly, at variance with other body cell types, the adaptive immune system of vertebrates results from an evolutive innovation (Muller et al. 2018). The hallmark of the adaptive cognitive immune system is the continuous exchange of energy, by generating combination somatic gene diversity of the lymphocyte antigenic receptors, and extensive lymphocyte renewal and turnover, with cell activation for clonal proliferation or deletion by cell death. The continuous exchange of information among the immune system allows for the continuous molecular and cellular antigenic environment perception. The sensory adaptive cognitive immune system is mandatory for organism viability and is related to the downstream holon-lymphocyte individuation that allow for "immunoception".

\section{- Immunoception and individuation through the dynamic adaptive immune system}

Cognitive paradigms (Cohen 1992) are related to perception, recognition, learning and memory that characterize immune processes and were discussed in the context of the immune system (Tauber 2013). This contributes to define the immune "self", discussed as a theory or metaphor by Tauber (Tauber 1994). Here, I propose to consider the recursive self-assertion/integration of holon-lymphocyte processes, with cell interactions and communication in the immune system, allowing for the antigenic molecular and cellular individuation of the holon-organism.

An individualized "singular" autonomous lymphocyte is conceptualized as a local "observer" of its environment, able of "immunoception": This means the dynamic perception of lymphocyte antigenic environment within the immunological context (tolerogen or immunogen, inflammatory). The immunoception occurs through singular receptors on lymphocytes that cognate, learn and memorize antigens, up to a cognitive lymphocyte population network that integrate the perception/reaction. Perception allows individual lymphocyte local reaction, and multi-form adaptation according to the immunological context perceived with other receptors/ligands interactions. The emergence of anamnestic functions preserves an internal lymphocyte network memory of the for current tolerance and a for more rapid and efficient secondary clonal immune responses. Then, immunoception complexifies from single cells to cell populations in various lymphoid tissues of the holonorganism, as a dynamic interactive lymphocyte network. At high level, immunoception insures the identity and integrity of the holobiont holon-organism. Defective immunoception as immunodeficiencies or defective regulation of lymphocyte proliferation, is lethal for the organism. 
As recalled, a grammar or chemical language, leads the lymphocytes and the immune system to have options according to the context, and they can respond in various ways. For that the lymphocyte proliferation and death is highly regulated. The biological default state of cell proliferation found generalization in the theory of organism (Soto et al. 2016). Then, during early lymphopoiesis, lymphocytes divide extensively according to their differentiation stage and the age of the organism (Vibert and Thomas-Vaslin 2017). Except for around ten percent's of lymphocytes that display internal autonomous proliferative activities and autoreactivities (Freitas et al. 1989), the proliferative default state is then normally repressed in most mature lymphocytes (Lorenz 2009) that wait as quiescent cells in young adults before to respond to antigens, according to the clonal selection theory. But with aging and cell senescence, the cellular signaling and control are dysregulated, allowing dynamic defaults (Fulop et al. 2014). Lymphocytes are sensible to various external inputs with complex signal strength and duration (van Panhuys 2016) for activation, and progression in the cell cycle, proliferation or death also depend on internal cell control (Heinzel et al. 2018). At the lymphocyte population level, proliferation is regulated by a network of idiotypic interactions and regulatory cells that mediate dominant tolerance for the preservation of the identity and integrity of the organism (Thomas-Vaslin 2014). Various experimental investigations are at the origin of the conclusion of non-determinist behavior of lymphocytes: Clonal selection processes and the adaptability of murine $B$ and $T$ lymphocytes occur according to the environment and the age of cells and organism (Thomas-Vaslin 1990) (Andrade et al. 1991; Thomas-Vaslin et al. 1991; Thomas-Vaslin et al. 1997a; Thomas-Vaslin and Feitas 1990; Thomas-Vaslin and Freitas 1989; Thomas-Vaslin et al. 1997b; Thomas-Vaslin et al. 1995). Probabilistic view of immunology was then proposed (Hodgkin 2007). Each lymphocyte evolves, reproduces and acts on others with its own biological time scale (Thomas-Vaslin 2015a), from hours for cells, to years for humans. Thus, among the various lymphocyte cell types, there is a high phenotypic and dynamic heterogeneity, with a great variation of cell proliferation rates and death: using mathematical models, these rates were estimated in T cell populations, during the course of perturbations that affect the "steady state" (Thomas-Vaslin et al. 2008). These rates evolve according to lymphocyte tissue localization and differentiation stages, but they also depend on the age of the organism that hosts them and of the genetic constraints with typical proliferative signatures (Vibert and Thomas-Vaslin 2017). Thus, lymphocytes across their internal genetic biodiversity, their antigen receptor singularity and local variable environment are submitted to "individuation processes": with recursive self-assertion/integration they continuously migrate and interact with other cells, and have a dynamic perception of their environmental antigens. According to this environmental context the lymphocytes have options: they can actively proliferate, up to 12 cell generations (with about 2000-4000 distributed identical clonal cells recirculate in humans) increasing their "self-assertion". But lymphocytes can also reenter into quiescence, or become senescent. Alternatively, they can die by activation of macro-autophagy or programmed cell death that leads to "cell suicide" or apoptosis (He et al. 2012). Such interactions with the environment, orient lymphocyte populations individual survival and functions (effector vs regulators) and globally their repertoire biodiversity evolve through time (Thomas-Vaslin et al. 2012). Consequently, the dynamics, turnover and life span of lymphocytes is not determined, but dependent on the diversity of their repertoire and activation and selection processes by the environment. 
The immune system constitutes one of the most complex fluid diversified and distributed tissue, with cognitive, autonomous and adaptive functions. We will now illustrate some processes of self-assertion/integration that occur in the holarchy, for the individuation of holon-lymphocytes, the organization of the immune system leading to the individuation of the holon-organism.

\section{- The immune system: not a defense but a conservation system}

Various theories were proposed and largely debated among immunologists, mathematicians, and philosophers about the immune system organization and cognitive systems properties (Maturana 2002; Maturana and Varela 1980) (Perelson and Weisbuch 1997), (Vaz 2011) (Vaz and Carvalho 2015). From a defense machine war historically perceived since vaccination developed, a critical approach of the classical view of the immune system, was given by (Coutinho et al. 1984) and Nelson Vaz (Vaz et al. 2006). Vaz proposed to replace the current metaphor of "host defense system against foreignness", by a "conservation" of system. Hence, conservation relates first to the "self-assertion". This insures the host molecular and cellular identity that start early in fetal life. These authors argue that the "defense" system that develops later in ontogeny during the infancy, is a teleological argument based on functionalism and neo-Darwinism, with intentionality related to selection pressure. On the contrary, they proposed that the immune system is an "exaptation": it is not instructed by pathogen or danger, but based on immune system auto-organization, and inheritance from other physiological systems during evolution (Ramos et al. 2006). The exaptation in immune system results, among others in the holobiont vertebrate organism, of the use of microbial integrase, to diversify the genes encoding the lymphocyte clonal receptors. This somatic gene diversification then allows for the "individuation" of lymphocytes. Nevertheless, the current view of an "adaptive" immunity with optimization of defense against pathogens remains a dominant concept among immunologists who mainly are interested in technologies driven methods to either stimulate the defense immune system (vaccination) or to control inflammatory diseases and cell proliferation with immunosuppression. As underlined by Tauber "Concinnity" would be more appropriate to integrate the immune system in a dynamic system.

A multiplicity of processes occurs in the immune system and create various levels of "information" and individuality. These processes allow for creative and recognition patterns at various biological levels (i) at the cell level, random genetic recombinations, nucleotide insertions and deletion and protein combination create Variable Region Molecules (VRM), (ii) at organism level, variable proliferation/death of lymphocyte clones, create dynamic repertoires of lymphocyte populations, from ontogeny to aging (iii) inter-generation acquired transmissions between organisms contribute to an historicity of the system.

\section{- The holon-lymphocyte individuation at the somatic level, with generation of diversity through Variable Region Molecules}

\section{○ Randomness}

Lymphocyte are exceptional cells, at variance with other body cell types: each lymphocyte "individualizes" at the somatic level, through the expression of a unique but stochastic Immunoglobulin-like antigen-receptor. Each lymphocyte, through genome variation processes that vary according to evolution and species, generates a singular Ig-like immunoreceptor type. In vertebrates each lymphocyte creates independently a molecular 
diversity, by random processes and generate hypervariable regions of the protein's receptor that is preformed before to cognate antigens. Such singular antigen receptor is encoded in mammals by somatic stochastic V-D-J gene rearrangements and nucleotide insertion/deletion, providing variation in the lymphocyte genome, from the germline encoded genes. Then, the random combination of various protein chain produces a unique dimeric immunoreceptor type, on each individual lymphocyte. This leads at the protein level, to the Variable Region Molecule, singular for each lymphocyte (Stewart 1994). Probabilistic events then also drive the activation, phenotype and regulation of proliferation/death of the billions of heterogeneous B and T lymphocytes (Heinzel et al. 2018).

\section{- Redundancy of molecular receptors and lymphocyte clones}

The redundancy of this single immunoreceptor, with about $10^{5}$ of copies per lymphocyte, insures the cell sensitivity to various quantities of antigens. B cells can secrete about two thousand antibodies per second (Jerne 1955). Then, the antigens act as a selective carrier and signal to the lymphocyte that recognizes molecular patterns and then adapts its behavior to the context. Eventually the lymphocyte proliferates to provide a clonal redundancy and efficiency of immune response against an "invader". Alternatively, it keeps quiescent and aware of a next variation context. These processes modify the diversity of lymphocytes repertoires across the different lymphoid tissues.

\section{- Degeneracy of cognition}

The de-generacy properties of the cognitive processes (Edelman and Gally 2001), meaning a "multiplicity principle" as proposed by (Ehresmann and Vanbremeersch 2007), allow for cross-reactivity of lymphocytes (Mason 1998). Degeneracy should not be confused with the degeneration as underlined by (Mason et al. 2015). The de-generacy of antigen cognition by the lymphocyte results from the interaction of singular amino acid receptor sequences (variable length of sequences from about 3 to 17 amino acids) with different antigens sequences (often nona-peptides), leading to various affinities and downstream signals to the lymphocyte. The VRM itself is antigenic, and the various idiotopes allow to interact with other lymphocytes (anti-idiotype). Then, the reactions allow to connect all lymphocyte together in a circular idiotypic dynamic network, as revealed by the Nobel prize (Jerne 1971) in the network hypothesis. As a consequence, the hyper-variable region of each specific and singular immunoreceptor per lymphocyte, allows the binding by degeneracy of thousands to millions of nonapeptides for each specific immunoreceptor (Mason 1998), with various energy binding (Hemmer et al. 2000; Hemmer et al. 1998). As underlined by immunologists (Coutinho et al. 1984), "In this network-centered perspective, the system's internal activity represents and defines its cognitive domain, and the system has no way (and no need) of distinguishing self from foreign". The lymphocyte repertoire then presents a high connectivity, is organism centered with autonomous, autopoietic activity, and is complete.

\section{- A connective dynamic network of lymphocytes to organize the Central and Peripheral Immune Systems.}

Lymphocytes with their own "identity" progressively differentiate and integrate their environment. Thus, during the ontogeny, there is progressive emergence of successive waves of lymphocytes, starting with B cells (Marcos et al. 1991). During the perinatal period, the first natural B-1 B cells secrete spontaneously (do not require 
activation by antigens) multi-reactive and autoreactive pentameric IgM immunoglobulins (IgM). These cells provide the "core" of an internal spontaneous highly connected autoreactive idiotypic network. Indeed, each VRM is itself an antigen, recognized by other lymphocytes in an idiotypic/anti-idiotype connective network (Jerne 1974; Jerne 1984). This central autoreactive "self-asserted" core of immunoglobulins is named the "Central Immune System" (CIS) and is autonomous (Coutinho and Bandeira 1989). With spontaneous lymphocyte activity and degeneracy of pattern recognition (low affinity and multi-reactivity), it contributes to the "self-assertion" of the organism and tolerance to "self" (Freitas et al. 1989).

This highly degenerated CIS core network precedes and then integrate the new diversified lymphocyte that differentiate from birth to build the Peripheral Immune System (PIS), with more "specific" and less degenerated receptors. Indeed, when the immune system matures, other types of B and T lymphocytes differentiate. B-2 cells provide other Immunoglobulin isotype production (IgG, IgE, IgA) with more affinity for antigens. These lymphocytes are sensitive to antigens interactions (pathogens or other antigens) that activate them. According to the clonal selection theory (Burnet 1957; Jerne 1971; Jerne 1984) upon antigenic activation they display high proliferative capacities, increasing the clone size by redundancy. They also orient their differentiation and functions according to the inflammation context encountered, increasing their self-assertion by proliferation, while integrating the changes from their environment and modifying it. The "antigen-centered view" of the immune system, support the role of the PIS. The PIS involving clonal selection is the most commonly studied since it is involved during immune responses in mature organisms for the destruction of pathogens, infected cells or tumor cells and is even challenged by vaccination. However, the CIS is important during the development and for the further regulation of the immune system. It supports of an organism-centered view of the immune system (Coutinho et al. 1984), to control the natural autoreactivity and insure dominant tolerance to self (Thomas-Vaslin 2014). Thus, self-assertion/integration processes insure the dynamics of the lymphocyte connective network, and balance between tolerance/inflammation in immune system.

\section{- Completeness of repertoires of lymphocytes for self-assertion and integration.}

Collectively, at the supra-clonal level, the lymphocytes constitute evolutive bio-diversified "repertoires". The theoretical diversified repertoire of all lymphocytes represents a potential of $10^{15}$ singular antigen complementary variable regions. However, only $10^{12}$ lymphocyte are available in an adult human, with around $10^{7}$ singular sequences (i.e. singular clonotypes but with redundancy of clones through proliferation). Hence, the Ig-like hypervariable region repertoire mimics all the potential antigens from our environment (estimated to $10^{17}$. The completeness of lymphocyte repertoires is thus related to the degeneracy. The diversity of the repertoire of lymphocytes populations can be quantified by various methods (Six et al. 2013). The specific amino acid sequence of the hypervariable regions can now be characterized by deep sequencing of lymphocyte DNA, generating billions of nucleotide and amino acid sequences that characterize each lymphocyte and their clones in a particular tissue of an organism. The analysis of lymphocyte repertoires provides snapshot "signatures" of the results of their self-assertion/integration processes at a given time. This allows to quantify the diversity and variation of the organism lymphocyte repertoires across time and the various lymphoid tissues that differentiate in the organism. 


\section{- Self-assertion and integration of the holobiont poly-genomic organism, and Lamarckian transmissions}

The variation in human immune systems are related to both heritable and non-heritable influences (Brodin and Davis 2017). Then, homozygote twins select individual divergent lymphocyte repertoires (Casanova and Abel 2015): they individualize immunologically, because they independently produce lymphocytes with stochastic somatic diversity, and then the lymphocyte repertoires is selected according to the antigenic environment they interact with. The concept of trace-process that drives the organization and memory/historicity of the immune system and organisms was proposed (Thomas-Vaslin 2017).

Inter-generation transmission between the mother and infant provides inter-generations acquired transmission and micro-chimerism in each organism, that influence the immunological context and responses of the immune system. This leads to a polygenomic organism with a hologenome, (Bordenstein and Theis 2015), where the DNA of human origin represents only $10 \%$ of the DNA of the organism. Various types of Lamarckian acquired transmission were discovered, occurring between the mother and the fetus, and then at birth. As such, the immune system is shaped by mother immune system (Lemke et al. 2004). The mother transmits, by selfassertion, some patterns of its own acquired immunological historicity. The fetus then integrate such variations of its mother-selected environment for his own individuation: it includes (i) during gestation, the materno-fetal transmission of mother immunological memory through her immunoglobulin idiotypic repertoire, via placental exchanges (Lemke et al. 2004); (ii) at birth, the transmission of mother vaginal and other microbiota (DominguezBello et al. 2016); (iii) post birth, the IgA and lymphocytes transmission through breast feeding and milk from the mother (Hassiotou et al. 2013); (iv) on the other side, the transmission of fetal cells and lymphocytes that differentiate and survive during decencies post-partum in the mother, and can influence her health (Khosrotehrani and Bianchi 2005).

Thus, while the immune system of a newborn is in development and not still immuno-competent, a dynamic equilibrium between self-assertion/integration in the various unicellular and multicellular micro-organisms emerges inside the holobiont, from the recursive network interactions and communication processes. The young holobiont holon-organism then results from the dynamic integration of the mother environment and its historicity.

Considering all individual lymphocyte diversity, it creates a dynamic network able to recognize (integrate) the variation of any cell or molecule from the environment and to adapt its proliferation/death (self-assertion). Thus, the network landscape of lymphocytes is in permanent "deformation" to individualize the organism repertoire and adapt it to the antigenic environment landscape that continuously changes. Therefore, the lymphocyte repertoire provides an internal dynamic image framework of the contextual historical antigenic environment encountered by each organism, as a supra-clonal memory network.

\section{- Balancing the diversity and redundancy of lymphocyte clones for a dialectic equilibrium allowing for the sustainability of the individual}

As a whole, the properties and adaptive emerging functions of the immune system evolve through time, and we previously provided illustrations of these processes (Thomas-Vaslin 2015b). We explained that in young developing organisms, there is a high lymphocyte production through proliferation, allowing for the somatic DNA 
modification and high clonal lymphocyte diversity (conferring the extensity of the system). Darwinian-like variation and selection process occurs: each lymphocyte cognate various antigens through its clonal receptor but also capture, by other receptors, the immunological tolerated or inflammatory context that orient its behavior. Positive selection allows for increase of the clonal size, thus clonal redundancy (conferring intensity to the system). In contrast, clone death is related to either "neglect" or active negative selection. In growing young individuals, the diversity/connectivity is maximized. This allows for a global exploration capacities and adaptation since more pathways are available to perform a same function (de-generacy), and then the resilience is improved. However, during the infancy, the efficiency is still low, since clones still have a poor redundancy, there is a low frequency of highly "specific" memory lymphocytes. Memory clones only differentiate post lymphocyte activation and selection processes. Then, with time, high affinity efficient clones are produced, selected and proliferate but at the detriment of diversity. This allows to progressively organize a mature immunocompetent repertoire allowing for the sustainability (viability) of the organism by balancing the diversity (connectivity) and the redundancy of clones. At the age of the sexual maturity a dynamic optimum is reached, balancing a huge production and diversity to be resilient, with a maximal efficiency with the redundancy and richness (high clonal frequency) of some clones, to fight a rapidly proliferating specific pathogen, unless it escapes through variation. In conclusion, the individuation process is a dialectic equilibrium between the diversity and redundancy of lymphocytes helped with degeneracy and memory properties that emerge. This dynamic equilibrium should insure the resilience and efficiency of the immune system, while facing the dynamic change of the environment and a internal race against aging that alter the diversification and lymphocyte production processes (ThomasVaslin et al. 2012). This behavior with a window of viability, is reminiscent of the dynamic equilibrium observed in other natural ecosystem and in economics (Lietaer et al. 2010).

\section{- Individuation emergence: supra-clonal immunological memory and dominant tolerance in the organism}

Individually and collectively the lymphocyte repertoires contribute to the dynamic "trace-process" of the continuous molecular individuation and variation (enablement/adaptation) of each lymphocyte and each organism across its life (Thomas-Vaslin 2017). I propose that the trace-processes leading to an internal memory of the immune system to sustain the viability of organisms occurs at various level of granularity:

(i) At the lower cell level, the somatic diversification of the genes of the antigen receptor (memoryless) in lymphocyte confers a molecular identity, the "self-assertion" of each lymphocyte. The redundancy amplifies the receptor but also the clone by cell proliferation. Each clone keeps trace of the number of cell divisions as a "cellular aging", and each lymphocyte from this clone individualizes: it integrates in its internal molecular memory the trace of the interactions with the dynamical entities network (lymphocytes, idiotypic antibody network and antigens), by staying in the cell cycle or return into quiescence (GO) but also by changing its phenotype. This

(ii) At the supra-clonal level, collective cell behavior occurs with swarm intelligence among lymphocytes: the molecular sensitive capacities of lymphocytes lead them to capture the context of their changing environment and cell neighbors. This leads to "integration" of flux of changes in a dynamic network of lymphocyte that are 
continuously replaced through life but keep some properties as network. This high level supra-clonal memory is emergent as a collective behavior. We have demonstrated the collective memory is dependent on the dynamical cell division that maintain the global lymphocyte network and functions and not on the persistence of individual "memory phenotype" cells (Bellier et al. 2003).

(iii) Regulatory lymphocytes

Mammals regulate their immune system by a functional dominant network of active regulatory lymphocytes. This lymphocyte network leads to the dominant self-tolerance at the level of the whole organism, thus is the result again of collective behavior and of emergence of new functions. We previously identified that regulatory T cells develop during the early ontogeny, with the close contact of epithelial thymic cells that express genetic "self" components (Le Douarin et al. 1996; Modigliani et al. 1995). Regulatory T cells, which only represent 1\% of all lymphocytes, then functionally suppress the activation and division of other lymphocytes. This allows for the maintenance of a state of dominant tolerance, preserving the identity and integrity at the level of the holonorganism. This dominant tolerance is tissue-specific of the "self" learned by lymphocytes on the thymic epithelium of a given genomic origin : it induces tolerance to tissues as skin and heart, but not to B cells diversified at the somatic level (Thomas-Vaslin et al. 1995); If T lymphocytes are experimentally confronted locally to an altered thymic epithelium (from a diabetic prone individual), then this local environment changes their integration, and it can result in autoimmune disease development (Thomas-Vaslin et al. 1997a). Thus, the learning of lymphocyte is established from local state, up to the level of a whole organism. We also revealed a "split tolerance" in vitro, since aggressive lymphocytes that are globally controlled and regulated in the complex whole organism of a tolerant individual are nevertheless fully reactive and aggressive under reductionist conditions in vitro (Thomas-Vaslin et al. 1995). In such altered conditions, the supra-clonal lymphocyte network interactions and regulations leading to the dominant tolerance and memory are not sustained. The molecular and cellular immunological driven individuation of the organism is thus related to emergence of collective behavior of millions of diversified lymphocytes, that developed progressively as a network of dynamic interactions and regulations process between lymphocytes and other cells, during the development of the organism leading to a swarm intelligence (Thomas-Vaslin 2014). Going beyond the popular clonal selection paradigm and self/non-self dualist discrimination that limit the comprehension of the organization of immune systems through decades, should results from a change of paradigm. Collectively, holons-lymphocyte behave and learn with a "swarm intelligence", following a few "regulators" that have acquired a previous experience (either mother transmitted or locally educated and integrated), and they dominate the collective distributed behavior. Then, the immune system by learning strategies, through their evolutive repertoires and idiotypic networks (Landmann et al. 2017; Menshikov et al. 2015) compute the state and wellness of the body (Cohen and Efroni 2019).

\section{- Impact of aging and environmental perturbations on the self-assertion and integration of holon-lymphocytes and holon-organisms}

Perturbations and shrinking of the diversified immunoreceptor repertoires can be quantified through various score and indexes as for the diversity of eco-systems. With time, one can observe clonal expansions and partial/total clonal deletion of lymphocyte. This shrinking in immunological biodiversity is current after middle- 
life in various species of mammals and represent a consequence of natural aging (Thomas-Vaslin et al. 2012) with alterations of lymphocyte repertoire landscapes (Thomas-Vaslin 2015a). Defective connections and perturbations in the regulatory network with lymphocyte oligoclonal expansions also occur in most immunopathologies (Vaz and Carvalho 2015), with decreased lymphocyte diversity and occurrence of autoimmunity (Landmann et al. 2017; Menshikov et al. 2015; Thomas-Vaslin 2014).

Then, top to down human-driven processes either conscious or unconscious, by orgons actions on natural holons, are able to influence the behaviors of holons-lymphocytes and organisms. According to the hygiene hypothesis there was co-evolution of symbiotic and pathogen-rich environment and immune systems (Sironi and Clerici 2010). Then, the diversified microbiota transmitted primarily from the mother vaginal flora drives the development of the newborn immune system. The hypothesis is that the microbiota is tolerized by mimicry of self (Root-Bernstein 2016) (Tauber 2016). However, alteration of correct interactions with the microbiota and its integration by the immune system lead to current chronic inflammatory pathologies and induce autoimmune diseases or allergies in western countries (Bach 2002): Newborn delivery through cesarean prevents mother microbiota transmission (Dominguez-Bello et al. 2016); defective early exposure to microorganisms in infants leads to type 1 diabetes (Vatanen et al. 2016). Thus, perturbation of the self-assertion and/or integration by lymphocytes, leads to altered education and function of the immune system, to pathologies and eventually death of organisms.

Since the last century, the emergence of medical biotechnologies (orgon action on natural holons) are able to orient the behavior of lymphocytes of the immune system. The principle of vaccination, as a deliberate immunization against lethal or highly pathologic known infections, triggers the efficiency of a few lymphocyte clones, by the amplification of the clonal redundancy to improve the immunological memory and the viability of the organism. On the other side, treatments like immunosuppression delete or inactivate lymphocytes decrease the functional biodiversity of lymphocyte repertoires. We previously observed an "immunological amnesia" in immunized mice when a transient depletion of dividing holon-lymphocyte was triggered (Bellier et al. 2003). Nevertheless, $60 \%$ of the holon-memory lymphocyte where still present as living clones, but appear disconnected to maintain a functional immune memory in the organism. Transient immunosuppression also accelerates the immunological aging, with risk of functional immunodeficiencies (Thomas-Vaslin et al. 2012). Thus, transient immunosuppression affects the self-assertion/integration of lymphocytes their renewal and diversity capacities, provokes the collapse of the system that can eventually reconstitute but some functions are altered. Finally, the emerging dynamic immunological anamnestic-individuation processes, required for the maintenance of organism identity and integrity are lost (Thomas-Vaslin 2015a).

Thus, although the emergent lymphocyte repertoire is complete, environment interactions and perturbations through time and aging reduce its diversity and functionalities; This impacts in turn the self-assertion/ integration and integrity of the organism and even orients the healthiness of ecosystems and societies. 


\section{A mathematical model of dynamical processes through holon reconfiguration, for self-assertion and integration at various levels}

In order to have a better understanding of our natural world from observations, analysis and synthesis of downward and top down causations (Simeonov 2010), we propose a basic mathematical approach based on an abstraction of diversified heterogenous living holon dynamics communicating together through selfassertion/integration processes and reconfiguration.

We now refer to the ontological framework originally proposed by Miquel concerning the individuation of an open system S. This system is viewed not as an object with properties of an individual, but as the permanent reconfiguration of heterogeneity condition R1 that act on the system (R1 are then context dependent) and its reconfiguration R2 (Miquel and Hwang 2016). We propose a similar multi-level hierarchical system that integrates lymphocytes, the immune system and the holobiont (with microbiota) organism in the multi-level environment $\mathrm{E}$ (Figure 1).

Here we make an analogy with the holon previously described. The holon (S) through boundary conditions $(\lambda)$ has some initial recursive relations $(R 1, R 2)$ with its local environment $(E)$. Through the progressive iterations (symbolizing division/proliferation, variation, migration) of initial recursive relations, it integrates $\left(\Phi_{1}\right)$ some entities from $E$, thus assimilating the "self-assertion" $\left(\Phi_{2}\right)$ from other living holons. This in fact corresponds to energy transfer required for communication, through bio-chemical ligand/receptors interactions at cell levels. Thus, energy transfer and communication dynamically go up and down through the multiple levels of the living system (Vecchi et al. 2018), between cells, organism (holons), and social-ecosystems/societies (orgons).

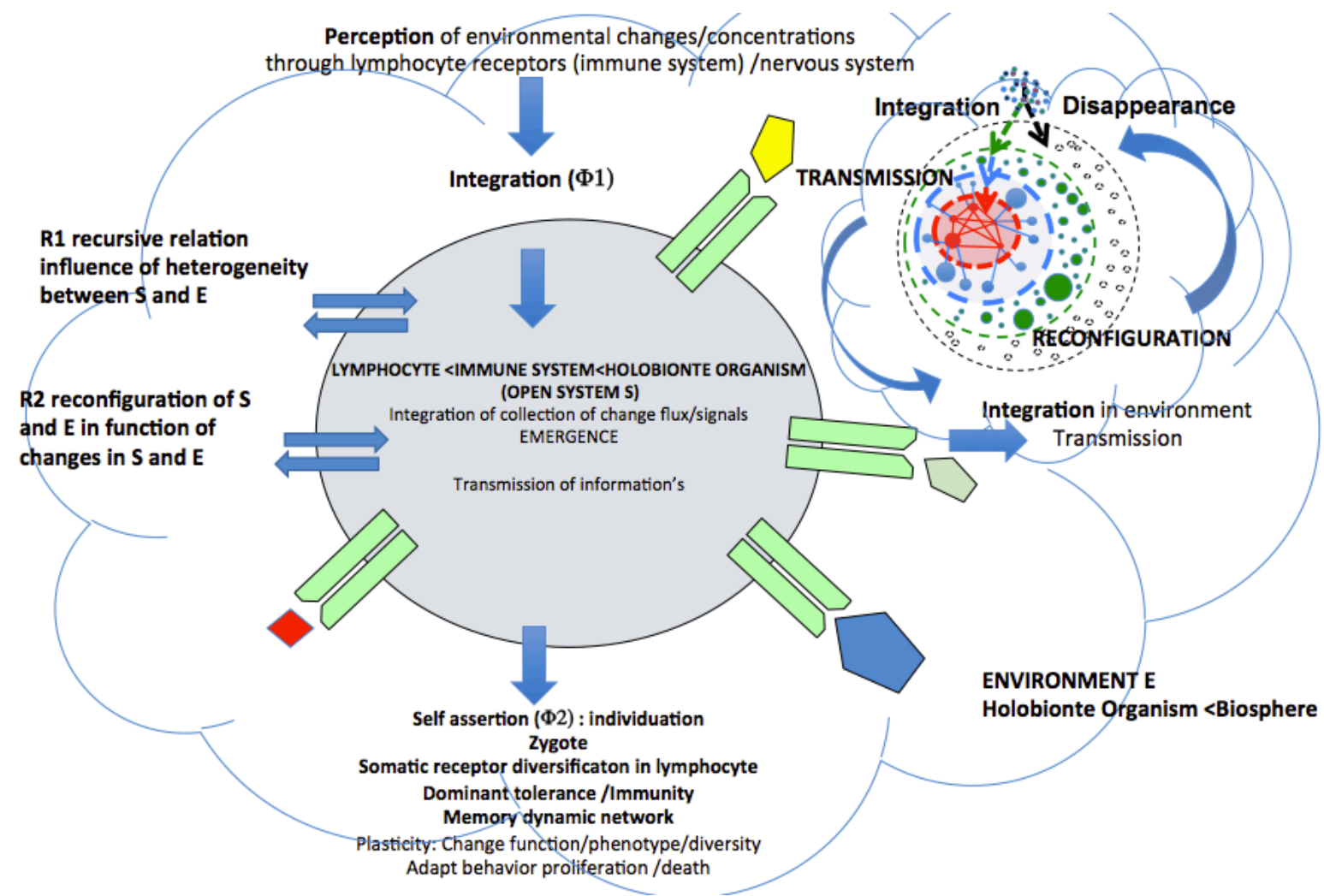

Figure 1 Homeo-dynamism of a holon-lymphocyte individuation with Janus faces (in reference to Koestler). 
The concept is that an open system $S$ dynamically exist as processes and flux of changes, on the basis of the integration ( $\Phi 1)$ of environmental changes (E) and self-assertion capacities ( $\Phi 2)$ that lead to individuation by permanent up-date changes of functions. This could concern cognitive systems, as the nervous system and the adaptive immune system. The picture exemplifies the perception of a Holon-lymphocyte (blue circle) that is a subsystem from the cognitive immune system, inside the holon-holobiont organism. The lymphocyte displays redundant but singular heterodimer immune-receptor on its cell surface (green), interacting with antigens/ligands (multicolor forms). These immuno-receptors (but also other receptors to chemokines, interleukins) allow for a recursive relation (R1) to integrate local changes from the contextual environment (the cloud), and to convert energy by cascades of events: receptors capture flux of signals, then transfer the energy by "signal transmission" inside the cell and then this leads to molecules interactions (molecular cell pathway's) inside the cell, up to the emergence of cell function changes (reconfiguration R2). This allows to maintain the cell viability by selfassertion/integration. Collectively, at the supra-clonal level, the lymphocyte populations are somatically diversified and are clonally expanded (self-assertion and redundancy). They interact together (with degenerative properties), communicate, and integrate each other state changes as a dynamic network. Alternatively, they die (dying cell in grey). The upper network refers to the idiotypic network with the integration /selection of new lymphocytes (Thomas-Vaslin 2014): the CIS core is a network with high connectivity (red clones) and the PIS (blue and green clones), display lower connectivity, but extension of clone size. This network is distributed and recirculate in the fluid environment of the body. Molecular and cellular diverse entities are rapidly renewed allowing for the plasticity and adaptability. The self-assertion/integration of lymphocytes in the network, allows the emergence of supra-clonal immunological memory (molecular and cellular identity of the holon-organism) required for the dominant tolerance to self (integrity of the holon-organism to maintain its individuation). This individuation of lymphocyte allows for supra-clonal emerging functions, balancing the efficiency and the resilience of the immune system that preserve the individuation of the holon-organism.

The immune system represents here a dynamic boundary network, required for the viability, the immunological supra-clonal memory with dominant tolerance to genetically heterogenous components assimilated as "self". The immune system functionality is mandatory for the survival and longevity of an organism, at the interface between the self-genetic cells, inherited cells, and multi-cellular organisms. The immune system itself evolves as a Janus communicating system leading: (i) to the self-assertion by producing somatic lymphocyte repertoire diversity; (ii) to the integration the molecular identity of the body cells that differentiate from the zygote.

The reconfiguration of the nodes of the network (R2) as cells, lymphocytes, molecules and Immunoglobulin-like receptors continuously evolved in time (before and after birth, during infancy, adult age and senescence until death) and in space (differentiation of cells in primary lymphoid organs, then migration, distribution/ recirculation inside the whole body, and local reactions).

Such permanent iterations of initial recursive relations (R1) and reconfigurations (R2) allow the system to evolve for self-assertion $\left(\Phi_{2}\right)$ and integration $\left(\Phi_{1}\right)$. This allows for a dynamic balance for the viability of the system (cell, organism) and its environment.

\section{- Generalization of the model of holon at any level of the living system}

This model could be extended to any level of the complexity of the living, considering that any sensory system as a cell or a multi-cellular organism, could be abstracted as a holon, a monad or a netbot node in a mathematical or computer model network (Simeonov and Ehresmann 2017). Recursive relations within the environment and interactions with heterogeneous living entities lead to update of states between the living entities, and emerging organization from cells up to macro-ecosystems and even artificial human driven organizations (Figure 2). Upstream and downstream fluxes of processes continuously occur. In such a complex system, feedback loops act to up or downregulate the system with consequences on its diversity and plasticity: 
(i) Positive feedback (more reproduction and thus variation) allows for more freedom and creativity by the system to generate more diversity and extensity (energy, entropy of the system), with a maximal potential exploration of the landscape as in a Waddington landscape allowing for multi-stability (Ferrell 2012). This occurs during the growth of a system.

(ii) Negative feedback loops constrain the system and decrease proliferation and variations: by decreasing the adaptive capacities it allows to stabilize the system, decreasing its entropy.

Emergence occurs from the dynamic network to lead to memory in the organism. Communication and flux of processes between organisms leads to ecosystems.

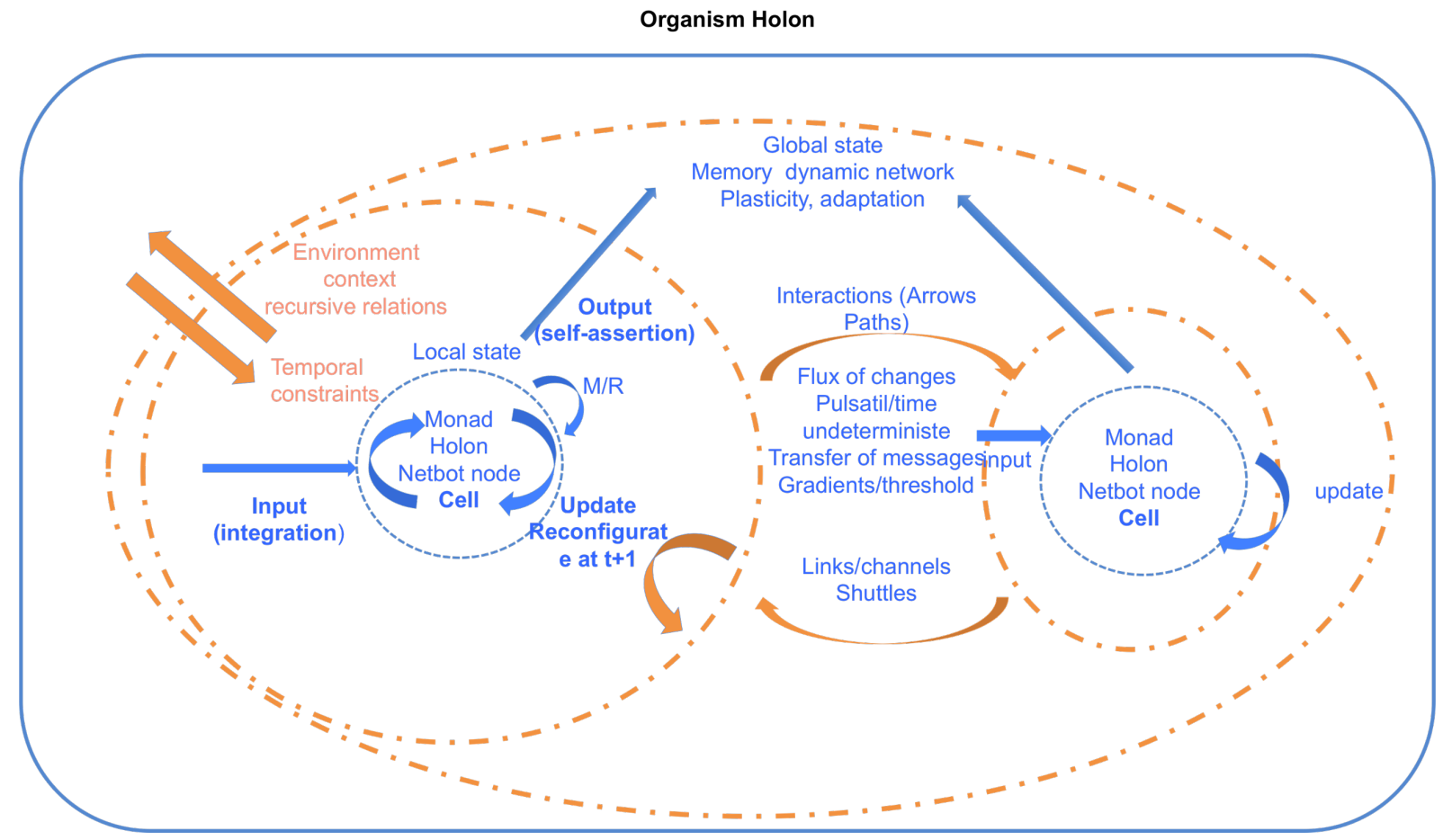

Figure 2: Dynamical Integration, self-assertion, interactions and update for adaptive holon-organism.

According to the level of observation, a same object, a holon, a monad or a botnet node in a mathematical /computer model network exists at a given time with a local state. Here we take the example of cell interaction in an organism, but similar processes could be abstracted between organisms interacting in social-ecosystems.

Integration of "input" from the environment changes the local state of the system, that metabolize/repair and reconfigurate as an "output" leading to its self-assertion: this output according to the enablement of the system leads to the reproduction of the living system, with variations, alternatively to death (selection). Interactions between heterogenous holons occur through flux of changes, with pulsatile time with non-determinist encounter, allowing above a given threshold of noise to transfer messages, and update the state of the different dynamic holons. This probabilistic models modifies through time the global state of the system at the upper level of cell populations, tissues, organs and finally organisms and socio-ecosystems. In such multi-level interactions, the recurrent integration/self-assertion result in emergence of collective behaviors at higher levels, with a global memory related to the transmission, plasticity, and adaptability of the systems. 


\section{Conclusions and perspectives}

A paradigm shift is proposed, from reductionist, static and statistic human-observer perspective, to a dynamic holistic view of interweaved living systems that develop with an historicity. This allows for a better integration of cognitive functions of multicellular and in particular of vertebrate organisms for the unconscious perception of molecular and cellular patterns by variable region molecule of lymphocytes from the adaptive immune system, with the emergence of immunological individuation.

Historically, human observers have a top-down perception of their environment. At their level of observation, they can only capture the macroscopic life and macro-ecosystems. Most of humans ignore the microscopic events that are downstream in their own organisms. The cognitive and abstraction capacities through the brain, allowing for the conscious perception, identification of entities are popular. The fuzziness of the top-down mental perception of human that concludes "a posteriori" from macro observations and statistics, on "selection" processes that allowed the best "adapted" individual or with a good fitness to survive is a current view. It is also used for the human-driven intervention in the environment and the development of technologies. But the cognition of organisms is not limited to neurons and nervous system. The perception of world should be enlarged with immune system which requires a bottom-up approach. The basic generic mathematical model presented here explains the recursive update of the low-level cell holon, as a cognitive adaptive and autonomous agent, leading to emergence of new functions and a collective anamnestic response of the past at the higher levels. The model allows to introduce the holon-lymphocyte that is at the origin of the immunological adaptive cognition and to explain the evolution and role of the immune systems for the individuation of metazoans.

The holon-lymphocyte self-assertion/integration through its specific somatic immunoreceptor expression, allows for the generation of global diversified and random lymphocyte repertoires. According to a dynamic connective network of lymphocytes, with supra-clonal regulations and feedbacks and shaping by the mother transmission, the emergence of the functional memory and dominant tolerance emerge, in the holon-holobiont organism to preserve, for a while, its global molecular and cellular identity and integrity and to persist as a species. For that the system can recruit some lymphocyte clones that activate and amplify or retract clonally, in a swarm-like intelligence of the dynamic environmental context. Then, through this integration, the lymphocyte repertoire diversity evolves through time as a moving landscape, confronted to the change of the intra-organism environment, until its death.

A retrospective understanding of the historicity of living, through species evolution and intergeneration nonheritable transmission, is of importance here to understand the occurrence of the collective intelligence that emerge in the adaptive immune system of metazoans. During the cross-evolution of species, the cognitive adaptive immune system appeared in invertebrates and vertebrates, with generation of the combinatory somatic diversity of lymphocyte receptors, due to the integration of genes from micro-organisms. The integration of microbial functions and ecosystem, has given advantages to some species, to survive: the generation of somatic diversity in lymphocytes, and the microbiota commensalism have co-evolved to give a molecular, cellular and functional individuality in each holobiont organism. This has generated a variety of immune systems, from innate to adaptive somatic leading to immunological memory and convergence for selective advantages (Muller et al. 2018) 
The peculiarity of each lymphocyte is to have an individuation, related to the expression of unique molecular receptors leading to an individual sensitivity to molecular patterns. Collectively, through the diversity of perception of each lymphocyte, at the lymphocyte population level it cognitive functions develop. The immune system organization as a system network with an internal autonomous activity, and the development of an organism-centered view of the dynamic microscopic life in the holobiont organism is a paradigm shift from the "defense system" that dominate historically with the clonal selection theory. The somatic diversity of holonlymphocyte in vertebrates through the adaptive immune system, generating a high dynamic connectivity network, is used here to explain the capacity of vertebrate holobiont holon-organisms to preserve their molecular and cellular identity and integrity through a emergent memory and dominant tolerance. The process of individuation was illustrated here with the help of the well now adaptive immune system of mammals. Nevertheless, analogies and convergence of genes and receptors have occurred independently during the evolution of vertebrates but also in invertebrates (Flajnik and Dupasquier 2004).

The evolution of the organization of multicellular-organism during ontogeny and disorganization during aging should also be considered in the individuation process. During the ontogeny, the human organism grows and complexifies, and has recursive interactions with its aquatic then terrestrial environment. In mammals, the maternal Lamarckian transmission contribute to the instruction and shaping of the immune system of the developing holobiont organism. The immunological cognition and individuation are complex functions that emerge from the differentiation and connectivity of an adaptive immune system that also develops communication during the development and later on, with the nervous system and the microbiota (Fung et al. 2017). With its identity the holon (cell, organism) permanently explores the ecosystems niches, with polygenomic origins: the "landscape", continuously deforms through time and imposes restrictions for the living organism. Such continuous exploration gives (or not) the capacities to survive and to reproduce so that the species (or a specific lymphocyte clone) can proliferate or not. The co-constitution of the cell/organism phenotype and functions emerge from low cell level and complexified interactions with the changing environment. This leads to a dynamic individuality of each cell/organism, and a network of organisms that regulate each other by feedbacks. The self-assertion/integration are complex parallel and sequential probabilistic processes occurring on various levels of the biological organization, from the cell to organisms with different time scales. This progressive organization allows for the emergence of complex links through the hierarchical interweaved levels. New functions emerge at the highest levels, as a global memory and capacities to remember and preserve a molecular and cellular identity inside the holobiont organism. A social collective memory also emerges from human populations.

With the change of paradigm on living, the perspective of a cell or a multicellular organism, thus a "monad" or holon, surviving and aging in its local environment is different: A holon-human (or even a lower scale a holonbacteria, a holon-lymphocyte) only exist through this daily dynamic emergent individuation and internalization of signals /update functions. The processes of perceptions/reactions, abstracted in dynamic living holons at various levels of the biological (cells and organisms) and ecological (species) organization allow for selfassertion/integration and individuation. Consequently, an organism is not defined by stable entities since they change every time at molecular and cellular level with new connections. Continuous reconfiguration occurs 
trough ontogeny, young healthy adults and healthy senescent humans. Then, the dynamic instability and fragility of living system is more apparent. A relative stability of system is observed at high levels by the human observer. However, when systems stop to grow and age, they disorganize and loose diversity.

With aging of organisms and organizations, if the process of signal input or update function is delayed first at cell level, then at tissue, organ and organism level, the flux of changes and the relational theory of biological systems to metabolize/replace and repair (Rosen 1958) could not be maintained. Then, the emerging biological functions and the viability of the ecosystem are impaired. Then, the recursive relation (R1) and the reconfiguration (R2) are altered. The resilience of the system and the global organization through highly dynamic network of multilevel interactions (molecule, cells, lymphocytes, immune system, organisms) decrease up to a threshold. The sustainability of organisms, ecosystems and even economy depends on a window of viability, with dynamic balance of diversity and interconnectivity that affects the efficiency and resilience (Lietaer et al. 2010). The resilience of economics systems could also be affected (Colon 2016) and the interference with healthiness of organisms should not be ignored. Pushing the systems to a maximal efficiency seems then detrimental for the resilience facing perturbations. Sudden unpredictable bifurcations can occur from microscopic to macroscopic level, with some critical threshold that can irreversibly push the system out of its viability domain, leading to collapse and death.

The difficulties to model and simulate interactive and recursive evolvable complex systems with high dimension and multiplicity of components was underlined. Some techniques were proposed to abstract signal integration in single neurons (Ugur and Conrad 2002). Then, use of graphical model and transition/interaction UML diagrams may enhance the evolvability of system with variation/selection. Transition diagrams have allowed us to simulate heterogenous systems with $\mathrm{T}$ cell differentiation, proliferation and selection according to recursive interactions and feedbacks with the lymphocyte environment (McEwan et al. 2011; Thomas-Vaslin 2015b; Thomas-Vaslin et al. 2013a; Thomas-Vaslin et al. 2013b). The Metabolism/Replacement (M/R) system, as proposed by Rosen developing the relational biology was reputed as non-computable on Turing machines, since it relates to relational causal chains that are circular. Recently, a computer model using activity/communication UML diagram was proposed (Zhang et al. 2016). Such graphical models and others (Simeonov 2010) should help to compute the input/output updates, thus the self-assertion/integration processes of living entities. The difficulty however remains to compute multi-level and multi-scale hierarchical systems with cognitive emergent functions as memory. Memory evolutive systems and Wandering Logic Intelligence (Ehresmann and Vanbremeersch 2007; Simeonov and Ehresmann 2017) to understand organism and ecosystems as dynamic whole, might now be considered to integrate immune system emerging functions in organism and the relationship to ecosystem perturbations.

In conclusion, the fact that the viability and persistence of humans, and other species, in the whole ecosystem is related to the downstream self-assertion/integration of cells, and the emerging functions of immune systems in organization and individuation should now be put forward. The global change of our living conditions with the rising of technologies, immuno-pathologies and neuroinflammatory disorders that occurred in the last century, should be viewed as defective self-assertion/integration processes. It results among others, from cross-talk disruptions and defective immunomodulation within the immune system-gut-brain systems (Fung et al. 2017). 
The difficulty remains now to model and compute such dynamic holarchy and take it in into consideration for ecological transition.

\section{References}

Andrade L, Huetz F, Poncet P, Thomas-Vaslin V, Goodhardt M, Coutinho A (1991) Biased VH gene expression in murine CD5 $B$ cells results from age-dependent cellular selection Eur J Immunol 21:2017-2023 doi:10.1002/eji.1830210908

Ashby WR (1962) Principles of the self-organizing system. Transactions of the University of Illinois Symposium. Pergamon Press, London, UK

Atlan $\mathrm{H}$ (1974) On a formal definition of organization J Theor Biol 45:295-304

Atlan H, Cohen IR (1998) Immune information, self-organization and meaning Int Immunol 10:711-717

Aubin JP, Bayen A, Saint-Pierre P (2011) Viability theory new directions. 2d edition edn. Springer,

Bach JF (2002) The effect of infection on susceptibility to autoimmune and allergic diseases N Engl J Med 347

Bellier B, Thomas-Vaslin V, Saron MF, Klatzmann D (2003) Turning immunological memory into amnesia by depletion of dividing T cells Proc Natl Acad Sci U S A 100:15017-15022 doi:10.1073/pnas.1936194100

Bordenstein SR, Theis KR (2015) Host Biology in Light of the Microbiome: Ten Principles of Holobionts and Hologenomes PLoS Biol 13:e1002226 doi:10.1371/journal.pbio.1002226

Bourgine P, Stewart J (2004) Autopoiesis and Cognition Artificial Life 10:327-345

Brodin P, Davis MM (2017) Human immune system variation Nat Rev Immunol 17:21-29 doi:10.1038/nri.2016.125

Burnet MF (1957) A modification of Jerne's theory of antibody production using the concept of clonal selection Aust J Sci 20:67

Capra F, Luisi PL (2014) The systems view of life- A unified vision. Cambridge University Press, Cambridge

Casanova JL, Abel L (2015) Disentangling inborn and acquired immunity in human twins Cell 160:13-15 doi:10.1016/j.cell.2014.12.029

Cohen IR (1992) The cognitive paradigm and the immunological homunculus Immunol Today 13:490-494. doi:10.1016/01675699(92)90024-2

Cohen IR, Efroni S (2019) The Immune System Computes the State of the Body: Crowd Wisdom, Machine Learning, and Immune Cell Reference Repertoires Help Manage Inflammation Front Immunol 10:10 doi:10.3389/fimmu.2019.00010

Colon C (2016) Modeling economic resilience. applied mathematics, Ecole polytechnique

Conrad M (1983) Adaptability: The Significance of Variability from Molecule to Ecosystem. Plenum Press, New York and London. doi:10.1007/978-1-4615-8327-1

Corre $\mathrm{G}$ et al. (2014) Stochastic fluctuations and distributed control of gene expression impact cellular memory PLoS One 9:e115574 doi:10.1371/journal.pone.0115574

Coutinho A, Bandeira A (1989) Tolerize one, tolerize them all: on assertion versus ignorance of self as the basis for tolerance Immunol Today 10:264-266

Coutinho A, Forni L, Holmberg D, Ivars F, Vaz N (1984) From an antigen-centered, clonal perspective of immune responses to an organism-centered, network perspective of autonomous activity in a self-referential immune system Immunol Rev 79:151-168

Dominguez-Bello MG et al. (2016) Partial restoration of the microbiota of cesarean-born infants via vaginal microbial transfer Nat Med doi:10.1038/nm.4039

Edelman GM, Gally JA (2001) Degeneracy and complexity in biological systems Proc Natl Acad Sci U S A 98:13763-13768 doi:10.1073/pnas.231499798

Ehresmann A, Vanbremeersch J-P (2007) Memory Evolutive Systems: hierarchy, emergence, cognition. Elsevier,

Ehresmann AC (2013) Modélisation 'catégoricienne' du vivant par émergence de monades multiformes. Presses Universitaires de Namur, Actes du Colloque. Presses Universitaires de Namur, Namur

Fagan MB (2011) Waddington redux: models and explanation in stem cell and systems biology Biology \& Philosophy 27:179213 doi:10.1007/s10539-011-9294-y

Ferrell James E (2012) Bistability, Bifurcations, and Waddington's Epigenetic Landscape Current Biology 22:R458-R466 doi:10.1016/j.cub.2012.03.045

Flajnik M, Dupasquier L (2004) Evolution of innate and adaptive immunity: can we draw a line? Trends in Immunology 25:640644

Flajnik MF, Kasahara M (2010) Origin and evolution of the adaptive immune system: genetic events and selective pressures Nat Rev Genet 11:47-59 doi:10.1038/nrg2703

Freitas A et al. (1989) B cell activities in normal unmanipulated mice Contrib Microbiol Immunol 11:1-26

Fulop T, Le Page A, Fortin C, Witkowski JM, Dupuis G, Larbi A (2014) Cellular signaling in the aging immune system Curr Opin Immunol 29C:105-111 doi:10.1016/j.coi.2014.05.007

Fung TC, Olson CA, Hsiao EY (2017) Interactions between the microbiota, immune and nervous systems in health and disease Nat Neurosci 20:145-155 doi:10.1038/nn.4476

Hassiotou F, Geddes DT, Hartmann PE (2013) Cells in human milk: state of the science J Hum Lact 29:171-182 doi:10.1177/0890334413477242 
He M-X, McLeod IX, Jia W, He Y-W (2012) Macroautophagy in T Lymphocyte Development and Function Frontiers in Immunology 3

Heinzel S, Marchingo JM, Horton MB, Hodgkin PD (2018) The regulation of lymphocyte activation and proliferation Curr Opin Immunol 51:32-38 doi:10.1016/j.coi.2018.01.002

Hemmer B, Jacobsen M, Sommer N (2000) Degeneracy in T-cell antigen recognition - implications for the pathogenesis of autoimmune diseases J Neuroimmunol 107:148-153

Hemmer B, Vergelli M, Pinilla C, Houghten R, Martin R (1998) Probing degeneracy in T-cell recognition using peptide combinatorial libraries Immunol Today 19:163-168

Hodgkin PD (2007) A probabilistic view of immunology: drawing parallels with physics Immunol Cell Biol 85:295-299 doi:10.1038/sj.icb.7100061

Jacquemart F, Thomas-Vaslin V (2016) L'évaluation globale des technologies. In: Bocquet B (ed) La Fièvre de l'évaluation Les Nouveaux Rendez-vous d'Archimède. Presses Universitaires du Septentrion, p 196

Jerne NK (1955) The natural selection theory of antibody formation Proc Nat Acad Sci 41:848

Jerne NK (1971) What precedes clonal selection ? In: Ciba Foundation Symposium : Ontogeny of acquired immunity. Elsevier, Amsterdam, p pp. 1

Jerne NK (1974) Towards a network theory of the immune system Ann Immunol (Paris) 125:373-389

Jerne NK (1984) Idiotypic networks and other preconceived ideas Immunol Rev 79:5

Jerne NK (1985) The generative grammar of the immune system Science 229:1057

Khosrotehrani K, Bianchi DW (2005) Multi-lineage potential of fetal cells in maternal tissue: a legacy in reverse J Cell Sci 118:1559-1563

Koestler A (1968) Beyond Reductionism- Proceedings of the Alpbach Symposium 1968-Holons and Holarchy of Arthur Koestler. Arthur Koestler and J. R. Smythies,

Landmann S, Preuss N, Behn U (2017) Self-tolerance and autoimmunity in a minimal model of the idiotypic network J Theor Biol 426:17-39 doi:10.1016/j.jtbi.2017.05.004

Lavelle C et al. (2008) From molecules to organisms: towards multiscale integrated models of biological systems Theoretical Biology Insights 1:13-22

Le Douarin N, Corbel C, Bandeira A, Thomas-Vaslin V, Modigliani Y, Coutinho A, Salaün J (1996) Evidence for a ThymusDependent Form of Tolerance that is Not Based on Elimination or Anergy of Reactive T cells Immunological reviews 149:35-53

Lemke H, Coutinho A, Lange H (2004) Lamarckian inheritance by somatically acquired maternal IgG phenotypes Trends in Immunology 25:180-186

Lietaer B, Ulanowicz R, Goerner SJ, McLaren N (2010) Is Our Monetary Structure a Systemic Cause for Financial Instability? Evidence and Remedies from Nature Journal of Futures Studies 14:89-108

Longo G, Montévil M (2013) Extended Criticality, Phase Spaces and Enablement in Biology Chaos, solition and fractals 55:6479

Longo G, Montévil M, Kauffman S (2012) No entailing laws, but enablement in the evolution of the biosphere:1379 doi:10.1145/2330784.2330946

Lorenz U (2009) SHP-1 and SHP-2 in T cells: two phosphatases functioning at many levels Immunol Rev 228:342-359 doi:10.1111/j.1600-065X.2008.00760.x

Marcos MAR, Gutierrez JC, Huetz F, Martinez-A C, Dieterlen-Lievre F (1991) Waves of B-lymphopoiesis in the establishment of the mouse B-cell compartment Scand J Immunol 34:129-135

Mason D (1998) A very high level of crossreactivity is an essential feature of the T-cell receptor Immunol Today 19:395-404

Mason PH, Dominguez DJ, Winter B, Grignolio A (2015) Hidden in plain view: degeneracy in complex systems Biosystems 128:1-8 doi:10.1016/j.biosystems.2014.12.003

McEwan CH, Bersini H, Klatzmann D, Thomas-Vaslin V, Six A (2011) Refitting Harel statecharts for systemic mathematical models in computational immunology. Paper presented at the 10th International Conference on Artificial Immune Systems (ICARIS), Cambridge,

Mella P (2009) The holonic revolution: Holons, Holarchies and holonic networks the gosht in the production machine vol 8. Pavia University Press,

Menshikov I, Beduleva L, Frolov M, Abisheva N, Khramova T, Stolyarova E, Fomina K (2015) The idiotypic network in the regulation of autoimmunity: Theoretical and experimental studies J Theor Biol 375:32-39 doi:10.1016/j.jtbi.2014.10.003

Miquel P, Hwang S (2016) From physical to biological individuation Progress in biophysics and molecular biology 122:51-57

Modigliani Y, Thomas-Vaslin V, Bandeira A, Coltey M, Le Douarin NM, Coutinho A, Salaun J (1995) Lymphocytes selected in allogeneic thymic epithelium mediate dominant tolerance toward tissue grafts of the thymic epithelium haplotype Proc Natl Acad Sci U S A 92:7555-7559.

Mossio M, Montevil M, Longo G (2016) Theoretical principles for biology: Organization Progress in biophysics and molecular biology doi:10.1016/j.pbiomolbio.2016.07.005

Muller V, de Boer RJ, Bonhoeffer S, Szathmary E (2018) An evolutionary perspective on the systems of adaptive immunity Biol Rev Camb Philos Soc 93:505-528 doi:10.1111/brv.12355

Naess A (1973) The shallow and the deep, long-range ecology movement. A summary Inquiry An Interdisciplinary Journal of Philosophy 16:95-100 doi:10.1080/00201747308601682

Paton R (1996) Metaphors, models and bioinformation.pdf> Biosystems 38:155-162 
Paton R (2002) Process, structure and context in relation to integrative biology. Special edition in memory of Michael Conrad. Biosystems 64:63-72

Perelson AS, Weisbuch G (1997) Immunology for physicists Rev Mod Phys 69:1219 - 1267 \%U http://www.genome.org/cgi/doi/1210.1101/gr.1215303.

Ramos GC, Vaz NM, Saalfeld K (2006) Wings for Flying, Lymphocytes for Defense: Spandrels, Exaptation and Specific Immunity Complexus 3:211-216 doi:10.1159/000095881

Root-Bernstein R (2016) Autoimmunity and the microbiome: T-cell receptor mimicry of "self" and microbial antigens mediates self tolerance in holobionts: The concepts of "holoimmunity" (TcR-mediated tolerance for the holobiont) and "holoautoimmunity" (loss of tolerance for the holobiont) are introduced Bioessays 38:1068-1083 doi:10.1002/bies.201600083

Rosen R (1958) A relational theory of biological systems Bulletin of mathematicals biophysics 20:245-260

Simeonov PL (2010) Integral biomathics: a post-Newtonian view into the logos of bios Progress in biophysics and molecular biology 102:85-121 doi:10.1016/j.pbiomolbio.2010.01.005

Simeonov PL, Ehresmann AC (2017) Some resonances between Eastern thought and Integral Biomathics in the framework of the WLIMES formalism for modelling living systems Progress in biophysics and molecular biology doi:10.1016/j.pbiomolbio.2017.05.014

Sironi M, Clerici M (2010) The hygiene hypothesis: an evolutionary perspective Microbes Infect 12:421-427 doi:10.1016/j.micinf.2010.02.002

Six A et al. (2013) The Past, Present, and Future of Immune Repertoire Biology - The Rise of Next-Generation Repertoire Analysis Front Immunol 4:413 doi:10.3389/fimmu.2013.00413

Soto AM et al. (2016) Toward a theory of organisms: Three founding principles in search of a useful integration Progress in biophysics and molecular biology doi:10.1016/j.pbiomolbio.2016.07.006

Stewart J (1993) Cognition without neurones adaptation, learning and memory in the immune system Cognition 5:187-202

Stewart J (1994) The primordial VRM system and the evolution of vertebrate immunity. R.G.Landes, Georgetown, Texas

Tauber A (2016) A hypothesis: establishing the microbiome through immune mimicry Bioessays 38:1062 doi:10.1002/bies.201600083)

Tauber Al (1994) The immune self Theory or metaphor? Cambridge university press, Cambridge

Tauber Al (2013) Immunology's theories of cognition Hist Philos Life Sci 35:239-264

Tauber Al (2014) Reconceiving autoimmunity: An overview J Theor Biol doi:10.1016/j.jtbi.2014.05.029

Thomas-Vaslin V (1990) Influence of cellular environment on the population dynamics and repertoire selection of B lymphocyte in the mice

Thomas-Vaslin V (2014) A complex immunological idiotypic network for maintenance of tolerance Front Immunol 5:369 doi:10.3389/fimmu.2014.00369

Thomas-Vaslin V (2015a) Complexité multi-échelle du système immunitaire: Evolution, du chaos aux fractales. In: Matériologiques $\mathrm{E}(\mathrm{ed})$ Le vivant critique et chaotique. Paris, p 333

Thomas-Vaslin V (2015b) Multi-scale complexity of the immune system : Evolution, from chaos to fractals. In: Nicolas Glade AS (ed) Le vivant critique et chaotique. pp 333-402

Thomas-Vaslin V (2017) Le rôle des traces dans le système immunitaire : des anticorps au corps vol 4. Des traces du corps au corps-trace, Paris CNRS éditions edn.,

Thomas-Vaslin V, Altes HK, de Boer RJ, Klatzmann D (2008) Comprehensive assessment and mathematical modeling of T cell population dynamics and homeostasis J Immunol 180:2240-2250

Thomas-Vaslin V, Andrade L, Freitas A, Coutinho A (1991) Clonal persistence of B lymphocytes in normal mice is determined by variable region-dependent selection Eur J Immunol 21:2239-2246.

Thomas-Vaslin V, Damotte D, Coltey M, Le Douarin NM, Coutinho A, Salaun J (1997a) Abnormal T cell selection on nod thymic epithelium is sufficient to induce autoimmune manifestations in C57BL/6 athymic nude mice Proc Natl Acad Sci U S A 94:4598-4603.

Thomas-Vaslin V, Feitas AA (1990) Population kinetics of peritoneal LPS-reactive B lymphocytes Int Immunol 2:73-81

Thomas-Vaslin V, Freitas AA (1989) Lymphocyte population kinetics during the development of the immune system. B cell persistence and life-span can be determined by the host environment International immunology 1:237-246

Thomas-Vaslin V, Salaun J, Coltey M, Vaigot P, Fucs R (1997b) Kinetics and repertoire selection of T cells derived from the early waves of fetal thymus colonization after thymus grafting in allogeneic nude recipients Scand $\mathrm{J}$ Immunol 45:482-486.

Thomas-Vaslin V, Salaun J, Gajdos B, Le Douarin N, Coutinho A, Bandeira A (1995) Thymic epithelium induces full tolerance to skin and heart but not to B lymphocyte grafts Eur J Immunol 25:438-445.

Thomas-Vaslin V, Six A, Bellier B, Klatzmann D (2013a) Lymphocyte Dynamics and Repertoires, Modeling. In: Dubitzky W, Wolkenhauer O, Cho K-H, Yokota H (eds) Encyclopedia of Systems Biology. Springer New York, New York, NY, pp 1149-1152. doi:10.1007/978-1-4419-9863-7 96

Thomas-Vaslin V, Six A, Ganascia JG, Bersini H (2013b) Dynamical and Mechanistic Reconstructive Approaches of T Lymphocyte Dynamics: Using Visual Modeling Languages to Bridge the Gap between Immunologists, Theoreticians, and Programmers Front Immunol 4:300 doi:10.3389/fimmu.2013.00300

Thomas-Vaslin V et al. (2012) Immunodepression \& Immunosuppression during aging. In: Portela MB (ed) Immunosuppression. InTech open acces publisher, Brazil, pp 125-146

Ugur A, Conrad M (2002) Techniques for enhancing neuronal evolvability Neurocomputing 42:239-265 
van Panhuys N (2016) TCR Signal Strength Alters T-DC Activation and Interaction Times and Directs the Outcome of Differentiation Frontiers in Immunology 7 doi:10.3389/fimmu.2016.00006

Vatanen T et al. (2016) Variation in Microbiome LPS Immunogenicity Contributes to Autoimmunity in Humans Cell 165:842853 doi:10.1016/j.cell.2016.04.007

Vaz N (2011) The Specificity of Immunologic Observations Constructivist Foundations 6:334-351

Vaz NM, Carvalho CR (2015) On the origin of immunopathology Journal of Theoretical Biology 375:61-70 doi:10.1016/j.jtbi.2014.06.006

Vaz NM, Ramos GC, Pordeus V, Carvalho CR (2006) The conservative physiology of the immune system. A non-metaphoric approach to immunological activity Clin Dev Immunol 13:133-142 doi:10.1080/17402520600877216

Vecchi D, Miquel P, Hernandez I (2018) From Biological Determination to Entangled Causation Acta Biotheoretica doi:10.1007/s10441-018-9339-6

Vibert J, Thomas-Vaslin V (2017) Modelling T cell proliferation: Dynamics heterogeneity depending on cell differentiation, age, and genetic background PLoS Comput Biol 13:e1005417 doi:10.1371/journal.pcbi.1005417

Yates FE (1994) Order and Complexity in Dynamical-Systems - Homeodynamics as a Generalized Mechanics for Biology Mathematical and Computer Modelling 19:49-74 doi:Doi 10.1016/0895-7177(94)90189-9

Zhang L, Williams RA, Gatherer D (2016) Rosen's (M,R) system in Unified Modelling Language Biosystems 139:29-36 doi:10.1016/j.biosystems.2015.12.006 